Research Article, Issue 2
Analytical Methods in Environmental Chemistry Journal
AMECJ

\title{
Microplastics, an emerging concern: A review of analytical techniques for detecting and quantifying microplastics
}

\author{
Verla Andrew Wirnkora, Enyoh Christian Eberea,* and Verla Evelyn Ngozi ${ }^{\text {b }}$
}

${ }^{a}$ Group Research in Analytical Chemistry, Environment and Climate change (GRACE\&CC), Department of Chemistry, Faculty of Science, Imo
State University, Owerri, Imo State, Nigeria
${ }^{b}$ Department of Environmental Technology, School of Environmental Technology Federal University of Technology, Owerri, Imo
State, Nigeria.

A R T I C L E I N F O:

Received 13 Feb 2019

Revised form 30 Apr 2019

Accepted 12 May 2019

Available online 17Jun 2019

Keywords:

Anthropogenic

Fragmentation

Health implications

Hyphenated methods

Matrices

Seafood

\begin{abstract}
A B S T RA C T
Microplastics are ubiquitous tiny plastic particles $(<5 \mathrm{~mm})$ nonbiodegradable and have large surface area in the environment or the body of living things due to anthropogenic activities or fragmentation of plastic debris. Though they have been found in sea food and human body, their health implications are still speculative. Moreover, a major reason for dearth of information on this topical issue is the lack of standard operating protocol for detecting and quantifying microplastics as a result of their presence in more complex environmental matrices. In the present review some methodologies for analyzing microplastics reported in the period 2000 to 2018 have been documented with the aim of assessing which methods is most suitable and in what matrix. The following methods have been studied: CHN analyzers, pyrolysisgas chromatography/mass spectroscopy (PyrGC/MS), optical microscopy, fourier transform infrared microspectroscopy (Micro-FTIR), raman microspectroscopy (RMS) and scanning electron microscopy with energy dispersive x-ray spectroscopy (SEM-EDS), effective for particles $<500 \mu \mathrm{m}$. However, the quality of result obtained strongly relies on good sampling and sample purification. Specifically, MicroRaman spectroscopy is best for particles of $<1 \mu \mathrm{m}$ while degradation process of plastics is best monitored with SEM-EDS. Generally, studies have been conducted with often a combination of two methods: one separating and the other quantifying which can be problematic moreso in living tissue where there is no harm reported as at the time of this study. Ultimately based on this study, microplastics have become a cause for concern and advance studies are required to unravel the potential risk of their presence in our food and environment.
\end{abstract}

\section{Introduction}

Plastics are organic polymers, synthesized from the polymerisation of monomers extracted from oil or gas. Since it first modern development in 1907 called "Bakelite", it global production rose from 0.3 billion tons in 2010 [1] to 348 million metric tons in 2017 [2]. Approximately $10 \%$ end up in the marine environment [3] and only a fraction of about $3 \%$ was recycled in 2016 . The plastics while in the environment breaks down to form debris. Many studies have reported that majority (60-80 Corresponding Author: Enyoh Christian Ebere

Email: Cenyoh@gmail.com

https://doi.org/10.24200/amecj.v2.i2.57
$\%$ ) of debris in marine environment are made up of plastics [4-6], which are further broken down to tiny particles through weathering processes. The tiny particles are defined as "microplastics" together with primary plastic particles manufactured at microsize dimensions [5,7].

Microplastics can simply be defined as small plastic particles in the environment. Term "micoplastics" was recently coined, although the occurrence of small plastic particles on beaches and in coastal waters was first reported in the 1970s [8]. The U.S. National Oceanic and Atmospheric Administration (NOAA) classified microplastics as less than $5 \mathrm{~mm}$ in diameter 
[5]. However, different authors have given different classifications of microplastics with numerous size-ranges. Graham and Thompson [9] classified microplastics with diameters of $<10 \mathrm{~mm}$, diameter of $<5 \mathrm{~mm}$ was given by Barnes et al. [5] and Betts [10], 2-6 $\mathrm{mm}$ by Derraik [3], $<2 \mathrm{~mm}$ and $<1 \mathrm{~mm}$ [11-13]. Their sources vary including cosmetics, clothing, and industrial processes via urban wastewater treatment etc. Microplastics are classified as primary microplastics and secondary microplastics. The primary microplastics are produced from anthropogenic means while secondary microplastics are derived from breakdown of larger plastic debris into microscopic plastic fragments [14].

Microplastics can be ubiquitous and remain in the environment at high levels for many years because of their difficulty in breaking down. In the last decade, many researchers have developed interest and conducted studies on microplastics due to their massive buildup in the environment [12,13,15-17].

Currently, their mobility and entire cycle in the environment is not yet known. They are more particularly in aquatic and marine ecosystems. Due to their persistence in the environment, they find their way and accumulate in the bodies and tissues of many organisms. When in the host organism they could easily undergo chemical exchange due to their large surface area. This may possibly pose some health issues to the host organisms. In addition, they serve as vector to pollutants whose health implications are already established; which include heavy metals (HMs) and persistent organic pollutants (POPs) (i.e polyaromatic hydrocarbons, PAHs, organochlorine pesticides, OCPs and polychlorinated biphenyls, PCBs). Many research reports have shown that PCBs are capable of attaching to the surface of plastics [18-21] and become bioavailable when injected by animals $[22,23]$. For heavy metals, studies by Holmes [24] and Rochman [25] reported their adsorption to plastics surface when suspended in the marine environment. Ashton and coworkers [26], also reported adsorption of heavy metals such as iron $(\mathrm{Fe})$, manganese $(\mathrm{Mn})$, aluminium
$(\mathrm{Al})$, lead $(\mathrm{Pb})$, copper $(\mathrm{Cu})$, silver $(\mathrm{Ag})$, zinc $(\mathrm{Zn})$ in seawater on virgin (new) polyethylene pellets. In the same study, heavy metals, such as $\mathrm{Cu}, \mathrm{Zn}$, $\mathrm{Fe}$, were found in higher concentration on plastic production pellets than local sediments in coastline of South West, England [26]. According to Holmes et al. [24, 27], the extent of adsorption of metals on plastics in marine environment is probably due to the weathering, adhesion to foreign material (viz organic matter) over time, surface area and availability of anionic active sites.

Many scientist worldwide have reported on the uptake of microplastics by various marine organisms such as fish, sandhoppers, sea turtle, crustacean and mussel $[7,11,28-30]$. Due to this, their digestive system may be blocked, thereby leading to potentially serious injuries [31]. Furthermore, microplastics have been found in table salts used for cooking, potable water and human excreta [32]. However, the health implications of microplastics are still scantly studied with no evidence of impacts on human. This is an emerging area of concern. The very scarce available evidence is currently under review by World Health Organization (WHO). Their objectives are to indentify gaps in evidence and create an agenda for research, in order to provide detailed information concerning risk pose to human by microplastics [33].

Researchers argued that the scantly research on microplastics have majorly centered on lack of standard operation protocols (SOP) or methodology for sampling, detecting and quantifying them in the environment [34-38]. Although, different methods have been developed and used by different researchers due to their presence in more complex environmental matrices $[35,36,39,40]$. A review by Klein et al. [41] summarized possible procedure provided by different researchers for analyzing microplastics in environmental matrix. The review describes the entire study process from sample collection to reporting of results (presented in Figure 1). One key aspect of some of the analytical methods is the extraction of microplastics from dissolving biomass using one or more fairly aggressive chemicals such as potassium hydroxide 
(KOH), hydrogen peroxide $\left(\mathrm{H}_{2} \mathrm{O}_{2}\right)$, perchloric acid $\left(\mathrm{HClO}_{4}\right)$ and nitric acid $\left(\mathrm{HNO}_{3}\right)$ which can be destructive to the plastic particles and thus not accurately identifying and quantifying their presence in a sample. These aggressive chemicals are best suited for extracting heavy metals from samples of soil [42-44], water [45,46] and sediment [47].

Microplastics quantification is simply based on differentiating or separating these particles from other matter whether inorganic (e.g. sediment) or organic (e.g. plant material). Density based methods have been applied by many researchers in order to separate lighter compartments of the sample from sediment in a marine environment $[35,36,39,48]$. Using the density based method, Song et al. [49], explained that interference from other organic particles poses a major problem when identifying microplastics as synthetic polymers. Other methods involve the use of enzymatic digestion and lipophilic dye Nile Red (9-diethylamino-5H-benzo $[\alpha]$ phenoxazine-5-one) quantitative differential staining for small microplastics ( $1 \mathrm{~mm}$ to $20 \mu \mathrm{m}$ ) in a samples [40, 50-52].

Here, we review common analytical techniques by which plastic types are identified, which can also be used in microplastic detection in the environment. These techniques are commonly used in analytical and environmental studies. They have been reported to be sensitive and accurate for indentifying and detecting microplastics in the environment.

\section{Sources of data}

Materials such as statistical bulletins, journals articles and conference/workshop/seminar papers were used for sourcing information. Web of Science and Google Scholar were two major scientific databases used to search for related articles and at least one of the following keywords needed to sample appear in

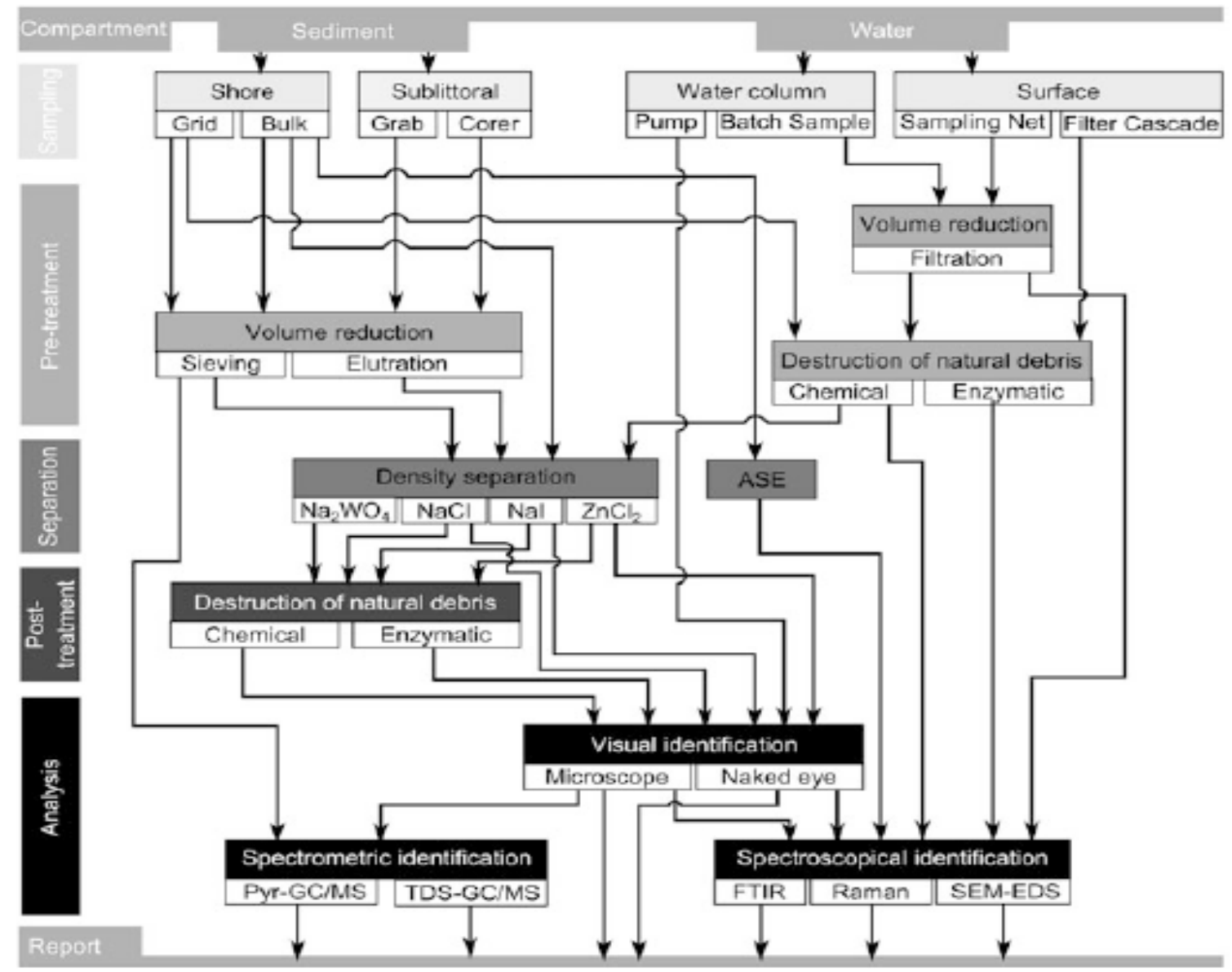

Fig. 1. Strategies provided by researchers for microplastics analysis from sampling to reporting results [41]. 
article's title or abstract: "Microplastics", "Plastics", "Marine", "Spectrophotometer", "Microscopy" and "Spectroscopy" (conducted in May, August and December 2018). One or more of the aforementioned keywords must be present in an article for the article to be included in the present review. All searches were restricted to peer-reviewed articles written in English that were published after 2000 to ensure review focus on recent literature on microplastics. Additionally, selected article prior to 2000 were included (e.g [53] and [54]) due to importance in the initial set of empirical studies.

\section{Experimental procedures and methods 3.1. CHN analyzers}

CHN Analyzer is a scientific instrument which can determine the concentrations of elements in a given sample using combustion technique. The analyzer is useful in the development and production of plastics. It identifies plastic materials and quantifies nitrogen, carbon, hydrogen, sulfur and oxygen contents in plastics. No sample digestion or toxic chemicals is required for Using it ,thus making it a reliable system [55].

Liliana and Guido [56] characterized plastics (pellets, powders and films) by the Thermo Scientific FLASH 2000 Elemental Analyzer. This instrument operates with dynamic flash combustion of the sample. A graphical flow diagram of the instrument is presented in Figure 2. The first thing was to introduce samples into the combustion reactor with oxygen using tin containers. The gases produced after combustion was transported by a helium flow to a layer containing copper, and then passed through a GC column, which separate these gases. The gases will be finally measured by a thermal conductivity detector (TCD). The measured gases revealed acrilonitrile (monomer), a main component of many types of compounds (polyacrylonitriles) such as plastics. The configuration can be achieved using either sulphur (CHNS) or oxygen (CHNO) respectively [56].

In an environment sample, the $\mathrm{CHN}$ analyzer will detects microplastics by the ability to identify materials with higher percentage of carbon, hydrogen and nitrogen content. The sizes of the samples are very small (a few milligrams), but may differ depending on system. Some samples matrix being heterogenous in nature and thus larger mass is preferred for their analysis using $\mathrm{CHN}$ analyzer. This method was modified by Morét-Ferguson and coworkers [57], using density separation with subsequent $\mathrm{C}: \mathrm{H}: \mathrm{N}$ analysis to identify the polymer origin of visually sorted microplastics. They concluded that the approach narrows the search for the potential polymer, thus enabling identification of microplastic particles by type, which requires no rigorous chemical analysis. However, the major drawbacks of this technique are (1) the relatively

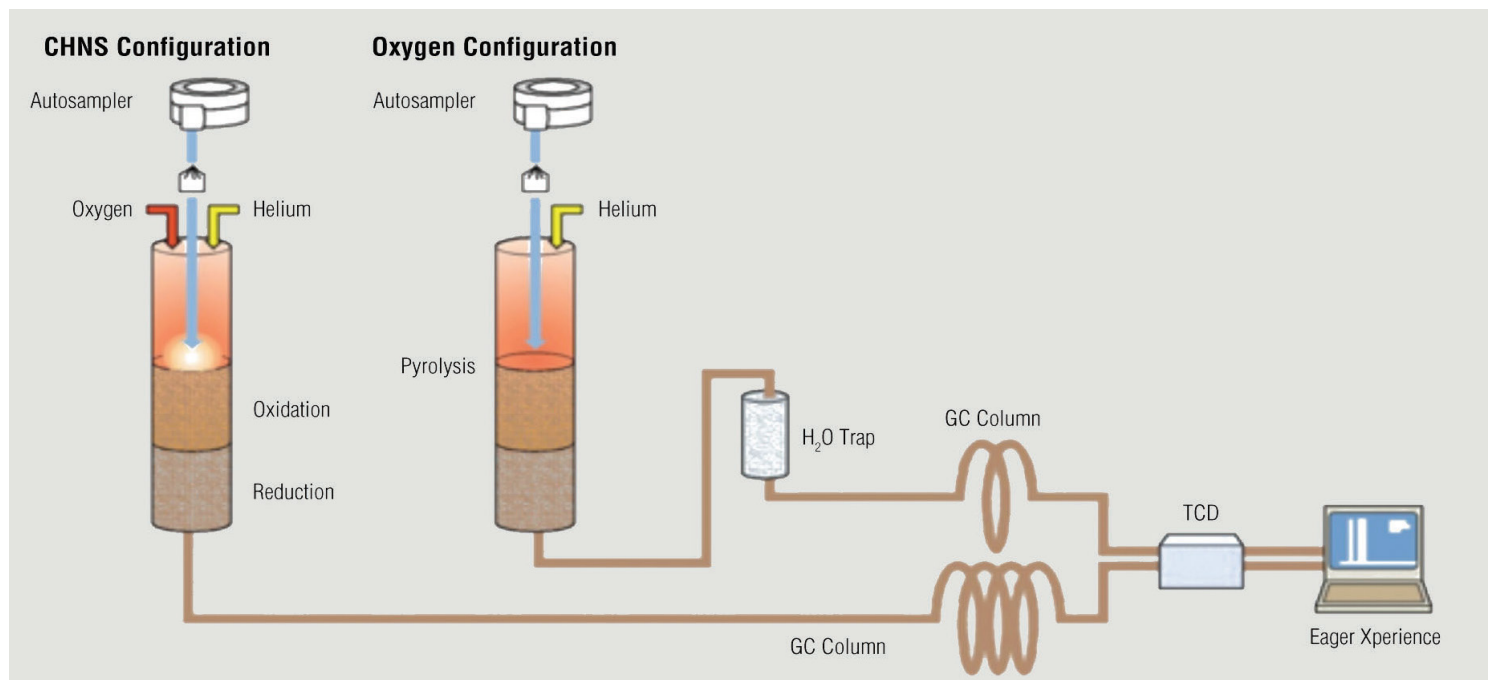

Fig. 2. CHNS/O configuration [56]. 
high time effort, which impede a high sample throughput and (2) not applicable to smaller particles [38].

\subsection{Pyrolysis-gas chromatography/mass spectrometry (PyrGC/MS)}

Pyrolysis-gas chromatography-mass spectrometry (PyrGC/MS) is a chemical analytical technique in which the sample are decomposed into smaller molecule through heating which are separated by gas chromatography and detected using mass spectrometry $[48,58]$. It is classified under mass spectrometry. The analytes for PyrGC/MS includes polymer, biomolecules and paint. A simple schematic representation of $\mathrm{PyrGC} / \mathrm{MS}$ process is presented in Figure 3.

The sample is placed in pyrolyzers and rapidly heated to $600-1000{ }^{\circ} \mathrm{C}$ (or $>1000{ }^{\circ} \mathrm{C}$, depending on the application). The heating techniques that can be employed include: isothermal furnace, inductive heating and resistive heating. Large molecules are decomposed into volatile fragments through the combustion $[59,60]$. The fragments will be separated by gas chromatography (GC), which will provide characteristic combustion products. These products will then be identified by mass spectroscopy (MS) and structural information elucidated by comparing them with reference of known pyrograms samples $[37,61]$.This method has been used by researchers to identify unknown plastic samples of different

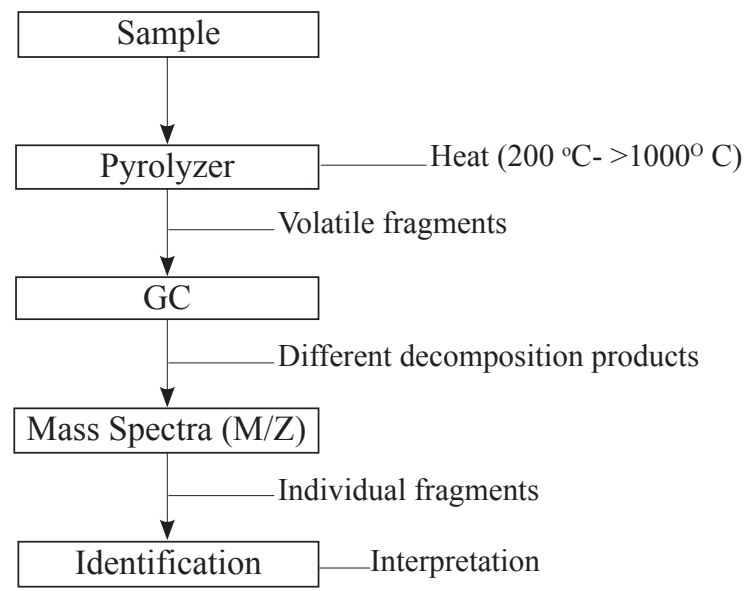

Fig. 3. A simple schematic representation of PyrGC/MS process.

polymer types and organic plastic additives (OPAs) [61,62]. A typical Pyrolysis-GC/MS chromatogram of a plastic sample is presented in Figure 4.

The major drawback is the manual place of sample particle into the pyrolyzer. This limits the size of particle that can be analyzed because only particles of a certain minimum size can be manipulated manually [38]. For this reason, samples are analyzed in sequence (one particle per run) and thus not suitable for routine monitoring programs where samples are analyzed in continuous manner. However, at 2015 promising pyrolysis-GC/MS approaches for the qualitative/quantitative analysis of microplastics on whole environmental sample filters was being developed. This will address the drawbacks of analyzing a particle per run.

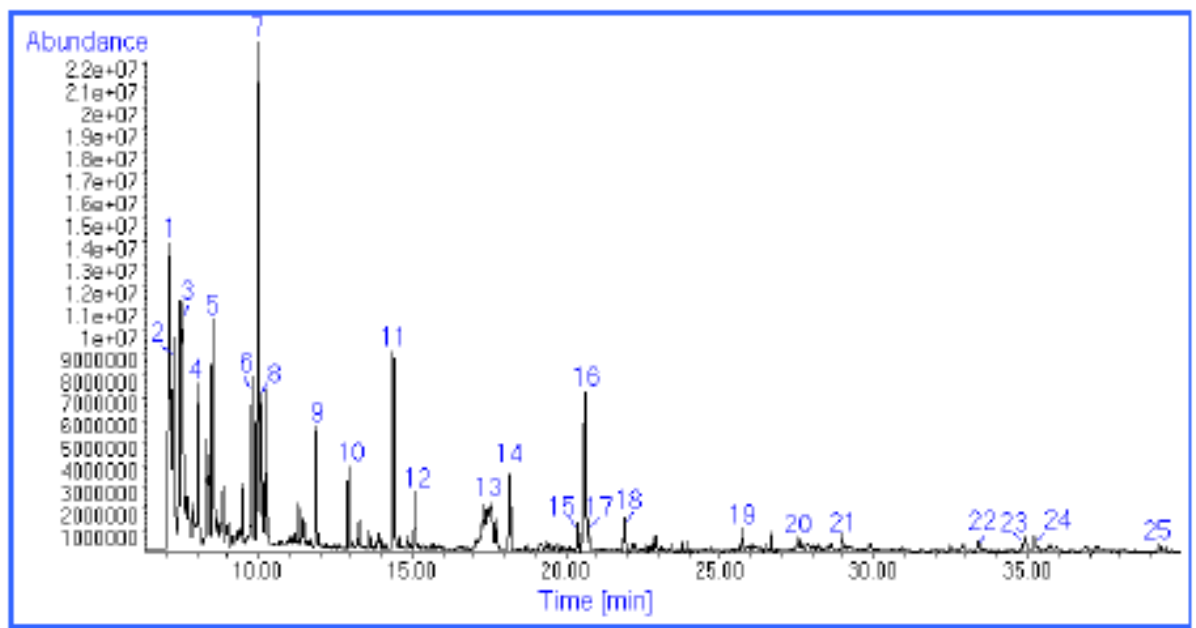

Fig. 4. A typical Pyrolysis-GC/MS chromatogram of a plastic sample pyrolyzed at $600{ }^{\circ} \mathrm{C}$, identified as flexible poly vinyl chloride (PVC) [62]. 


\subsection{Optical Microscopy}

Optical microscopy is the use of optical microscope (light microscope) to magnify images of small subjects using visible light and a system of lenses. The image from an optical microscope can be captured by normal, photosensitive cameras to generate a micrograph. This method is based on visual identification under a microscope. Visual sorting works well in separating large microplastics as well as separating potential microplastics from other organic or inorganic material in the sample residues [34,57] whereas dissection microscope is used in sorting smaller microplastic particles [63].

The use of this method has been reported in literature $[40,52,64]$. Wagner et al [40] used two reflected-light stereozoom microscopes (Leica S8APO and S6D) with digital CCD cameras (Leica DFC 420 and 320) for initial documentation, gut dissection, and pre-screening of any observed particles that visually resembled microplastics in fish samples. The optical microscopy was conducted at $6.3 \mathrm{x}-80 \mathrm{x}$ with a minimum resolution of approximately $10 \mu \mathrm{m}$ [52]. Wang et al [67] also used optical microscope for analyses of microplastics in ocean trawl and fish guts.

This method can be aided by staining using dyes such as Nile Red $[52,64]$. Samples will be treated first with the dye solution (often $1 \mathrm{~mL}$ ) for 48 hours under a fume cupboard until all moisture evaporated to form a dyed membrane. Subsequently, the dyed membrane filters were photographed using a camera under Ultra-violet (UV) light. Example of a useful camera is the Pentax K-30 with resolution $2420 \times 2343$ used by Matthias and coworkers [64] in their study.

The dye solution can be prepared using different extraction solvent such as acetone, chloroform and n-hexane. Chloroform with recovery rates of 83.3 $\%$ was reported to be most suitable solvent for the group of high-density and low-density polyethylene (HDPE, LDPE), polypropylene (PP) and PVC $[64,65]$. However, the findings of Shim et al [66] implicated $n$-hexane to be most effective for PE and PP, whereas PET and PA were not detectable. The variation in solvent efficiency in detecting the different microplastic type could be due to different surface and density properties of the microplastic materials. Also, a typical visually identified stained microplastics under an optical microscope is shown in Figure 5.

It is asserted by Wang et al [67] that optical microscopy enables morphological classification of particles or fibers types, quantification of particle size ranges and fiber lengths presents in a sample. However, it is suggested by Hidalgo-Ruz et al. [34] that for particles $<500 \mathrm{~mm}$, ordinary visual sorting with the naked eye or hand lens should not be applied. This may cause misidentification of particles with high probability. To sort visually, there are factors that should be considered generally, which they include source, type, shape, degradation stage, and color of the particles [34,57], which is extremely time-consuming. Martin and Gunner [38] explained that, "even an experienced person cannot discriminate all potential microplastic particles unambiguously from sand grains, chitin fragments, diatom frustule fragments etc." Thus the error rate of this method reported ranges from $20 \%$ [68] to $70 \%$ [34], which increases as particle size decreases. Therefore, a size limit of $1 \mathrm{~mm}$ was recommended for visual sorting [34,57].

\subsection{Fourier Transform InfraRed Microspectroscopy (Micro-FTIR)}

Fourier transform infrared (FTIR) microspectroscopy is a technique which produces molecular microscopic images from samples. The instrument allows observation of spectra measured from regions as small as 5 microns across because it uses an infrared microscope. The spectra correspond to specific chemical bonds between atoms which makes it possible to identify the exact composition of the particle [69]. In Micro-FTIR, two feasible measuring modes are used viz reflectance and transmittance [70]. The former (i.e. reflectance mode) handles difficult spectra obtained from measurements of irregularly-shaped microplastics that may not be interpretable due to refractive error [71]. The later mode (i.e. transmittance mode) handles the total absorption patterns and 


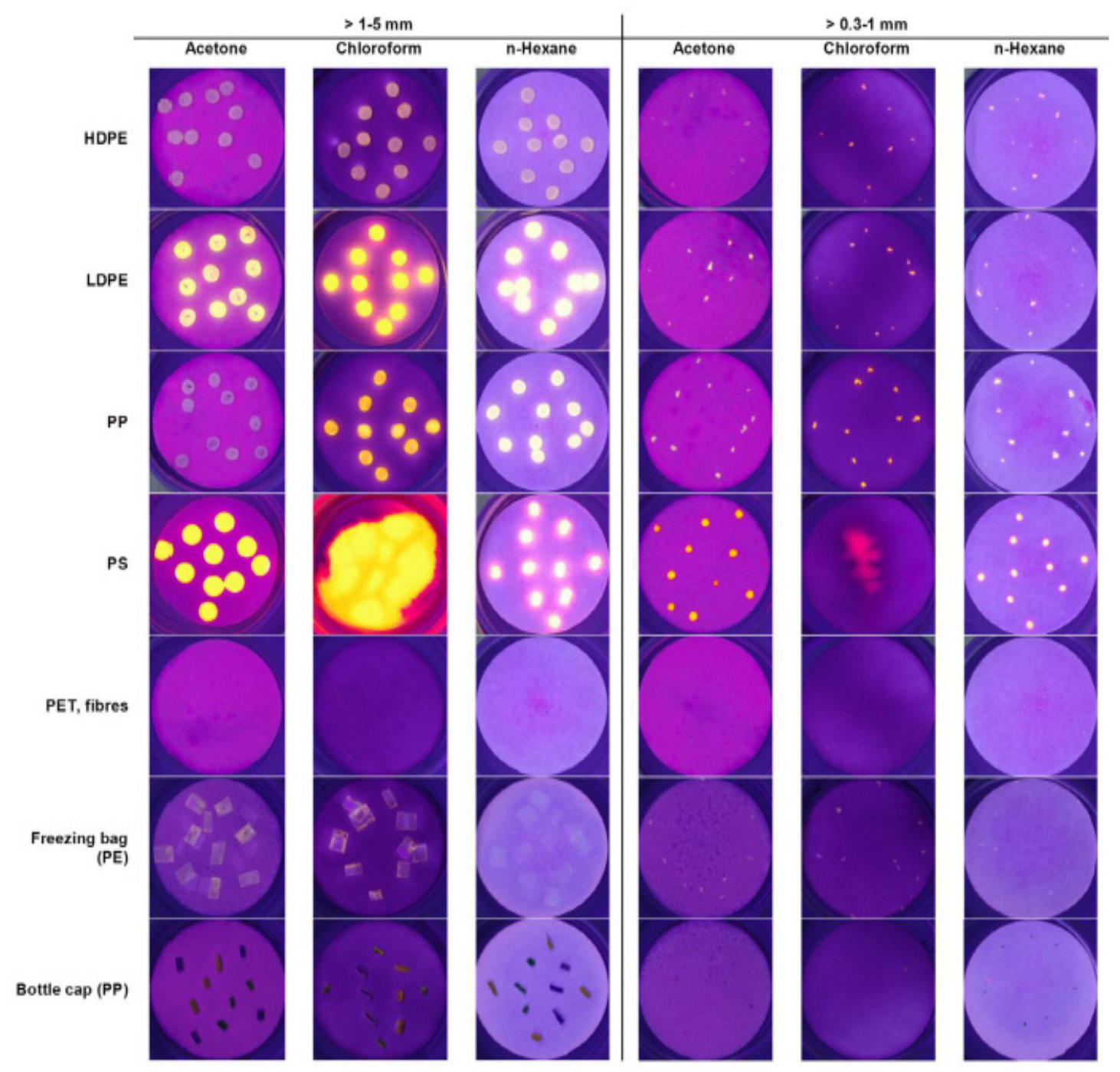

Fig. 5. A typical visually identified stained microplastics under an optical microscope [64].

uses IR transparent filters (e.g. aluminium oxide). Furthermore, it can only be limited by a certain thickness of the microplastics sample [38]. In addition, the use of micro-ATR (Attenuated Total Reflectance) in combination with microscopy enables the direct measurement on the sample filter without the need for manual handling of particles, when IR spectra are collected at the surface of a particle [40,70-72].

The micro-FTIR method has been used on biological samples such as articular cartilage [73] and to track microplastics in the environment with Attenuated Total Reflectance (ATR) $[40,73,72]$ and Focal Plane Array-Based Reflectance [38,70,74]. Wagner [40] and Bradley et al [72] both used the Thermo Scientific Nicolet Continuum FTIR Microscope with 10x optical objective, 15x IR objective, and a Nexus 470 spectrometer with attenuated total reflectance (ATR) (diamond and Ge-ATR). In the study, majority of the particles were analyzed either on glass slides or directly on filter. All acquired FTIR spectra were compared to quantitative matches from commercial FTIR libraries. In addition, in Figure 6, FTIR spectra of a microplastic fiber on filter from a river water sample are shown.

Kerstin and Federik [69] screened microplastic particles in and down-stream a wastewater treatment plant with a Bruker FTIR Tensor in attenuated total reflectance (ATR) mode equipped with a diamond 


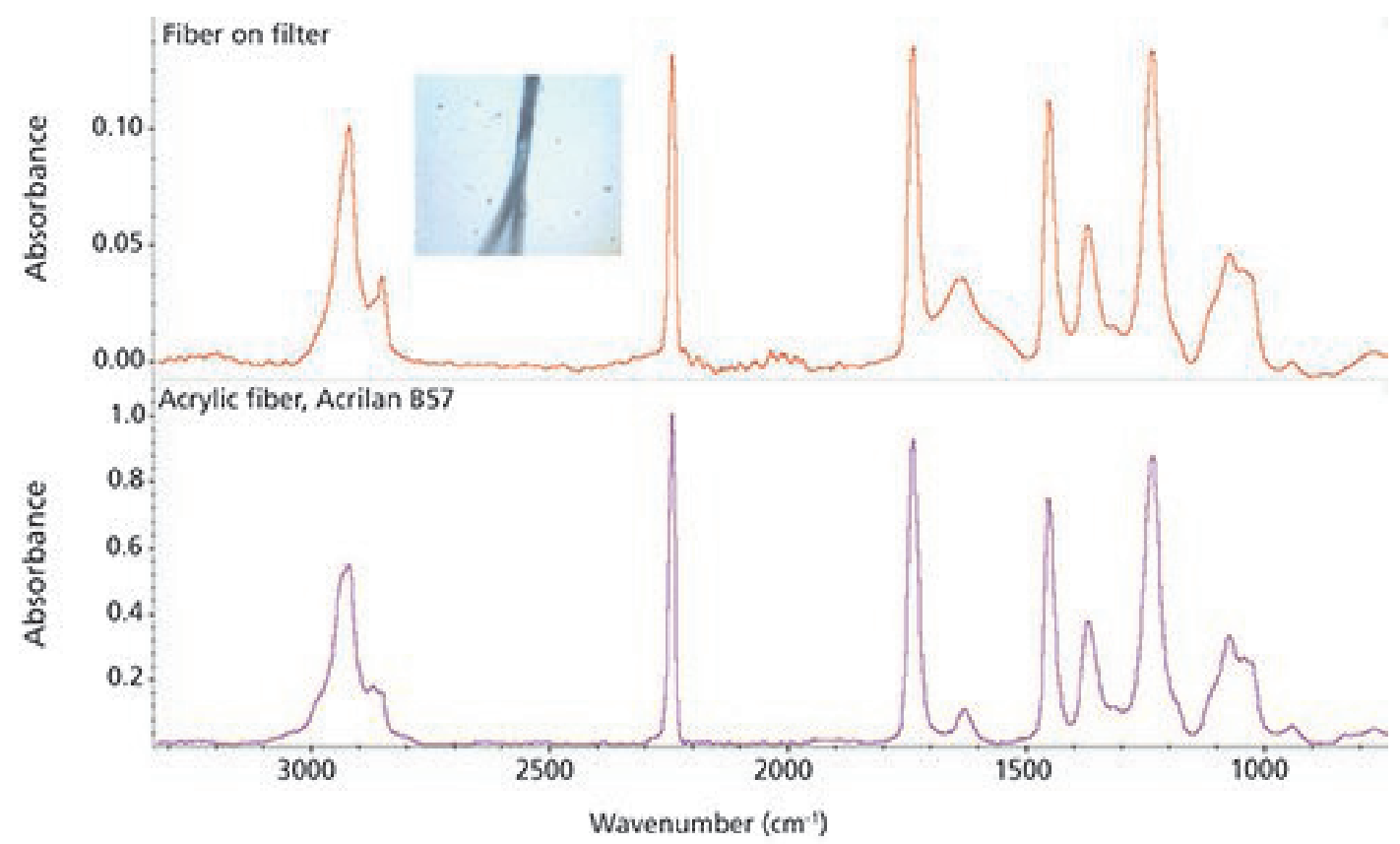

Fig. 6. FTIR spectra of a microplastic fiber on filter from a river water sample. The top spectrum is from Nicolet iN5 microscope fitted with Ge-ATR; the lower spectrum is a library search result [72].

crystal. Different plastic fragments $(\geq 300 \mu \mathrm{m})$ were reportedly found in wastewater treatment plant. Alexander et al. [74] used the FPA based reflectance micro-FT-IR imaging to identify and quantify microplastics in wastewater. The authors concluded that the tool is good for identifying and quantifying microplastics in wastewater and also to determine the abundance of microplastics in other organic-rich environments, such as peat soils [74]. This FPA based micro-FTIR spectroscopy is a very promising technique for verifying polymer origin of microplastic particles. Martin and Gunner [38] recommended for use in monitoring programs on microplastics.

Micro-FTIR enables identification of repetitive fingerprint-like molecular composition of plastic polymers for a clear assignment of a sample to a certain polymer origin. It offers the possibility of accurate identification of plastic polymer particles according to their characteristic IR spectra [15$17,48,71,75]$, simultaneously record several thousand spectra within an area with a single measurement and thus the generation of chemical images (Fig. 7) [38]. In figure 7, the analysis was done by FPA based micro-FTIR spectroscopy. The intensity of the chosen spectral bands is reflected by the color scale according to peak area (bluish color scale intensity of the peak 1,931-1,832 $\mathrm{cm}^{-1}$; reddish color scale intensity of the peak 2981-2780 $\mathrm{cm}^{-1}$ ). This enabled clear identification of a quartz particles in light blue (a) at band of 1931-1832 $\mathrm{cm}^{-1}$ and a polyethylene particle in orange (b) at band of 2981-2780 $\mathrm{cm}^{-1}$ in a sample.

The simplicity of this method is in both sampling and analyzing. Samples are simply

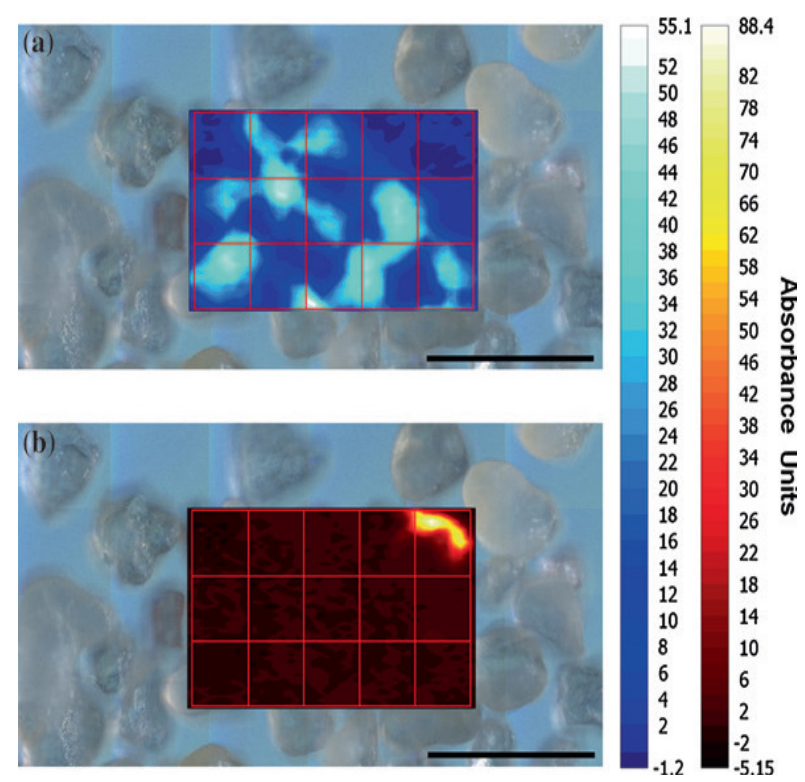

Fig. 7. Chemical image of an integration of typical spectral bands [38]. 
filtered and analyzed directly on the dried filter without further sample preparation. This enables the rapid assessment of microplastic encroachment and can assist in the development of remediation techniques [72]. However, it is extremely timeconsuming when targeting the whole sample filter surface at a high spatial resolution because it uses only a single detector element, which happens to be limitation of this technique [15,71].

\subsection{Raman micro-spectroscopy (RMS)}

Raman spectroscopy is a "surface technique", thus large, visually sorted microplastic particles can be analyzed and the technique can also be coupled with microscopy. Raman micro-spectroscopy is straightforward and uses a scattering technique. The simple principle of this technique is measuring the wavelength and intensity of inelastically scattered light from molecules caused by a monochromatic light. The Raman scattered light occurs at wavelengths that are shifted from incident light by the energies of molecular vibrations giving out spectra (Fig. 8). A very small volume $(<1 \mu \mathrm{m}$ in diameter) of the sample can generate the Raman spectra which allow the identification of species present in that volume [76].

The instrument consists of a standard optical microscope, an excitation laser, a notch filter, a monochromator, and a sensitive detector (such as a charge-coupled device (CCD), or photomultiplier tube (PMT)). The notch filter is used to block elastically scattered light which would otherwise overwhelm the weak signal from the Raman or inelastically scattered photons ( $1 / 10^{6}$ scattered photons). The Raman scattered light may be dispersed according to wavelength and detected by a CCD as shown in Figure 8 . Angel et al [53] stated that when a UV laser source is used for Raman microspectroscopy (RMS), then ultraviolet microscopes and UV aided optics must be used. Earlier studies by Taylor et al [78] and Adrian et al [79] have expressed the suitability of RMS for the microscopic examination of minerals, materials such as polymers and ceramics, cells, proteins and forensic trace evidence.

RMS have been used by a lot of researchers for detecting microplastics with high reliability in marine environment $[7,16,28,36,80]$ and for testing simulated microplastics polluted water [81]. Wagner et al [40] performed the analyses

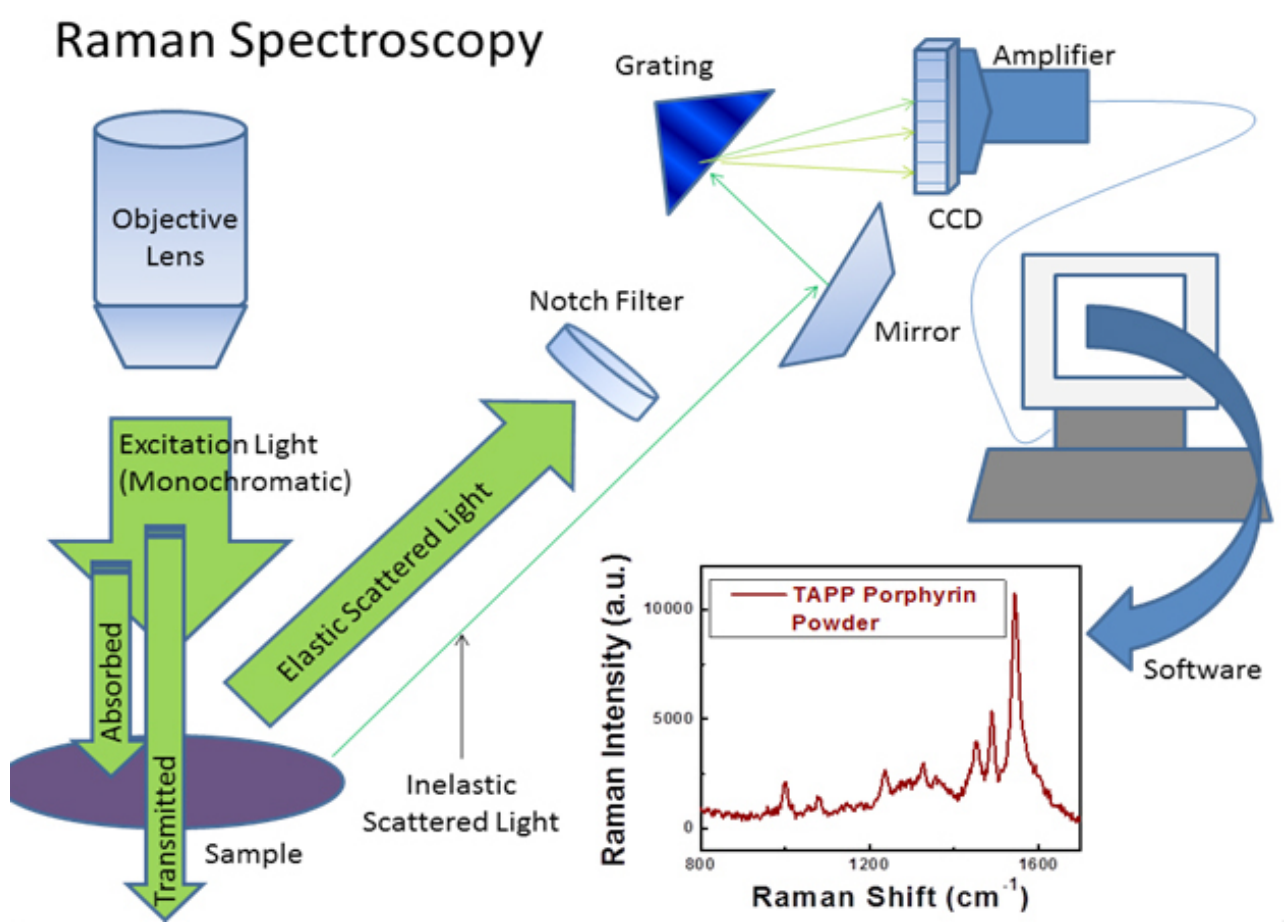

Fig. 8. Schematic for process involved in collecting Raman spectra. A Raman spectrum for tetra(4-aminophenyl) porphyrin (TAPP) powder is shown [77]. 
on ocean trawl and fish using both Renishaw inVia and Bruker Senterra dispersive Raman microscopes with $785 \mathrm{~nm}$ and $532 \mathrm{~nm}$ lasers. In the study, analytical laser optimization was achieved using several different objectives $(5 \mathrm{x}, 20 \mathrm{x}, 50 \mathrm{x}$ and 100x). The author marched the Raman spectra obtained with spectral matching performed using GRAMS software, which was equipped with commercially available Raman spectral libraries. Rocchia et al [81] simulated microplastics polluted water. A few milligrams of three different reference materials (irregularly shaped polyethylene particles sieved at 74 microns, polystyrene-divinylbenzene PS-DVB microspheres sieved between 37-74 microns and polyethylene-titanium dioxide PE$\mathrm{TiO}_{2}$ microspheres with a size range of 27-45 micron) were used to simulate microplastic debris with different particle sizes in $0.5 \mathrm{~L}$ of water. The Raman spectra data were collected using the DXR2xi Raman imaging microscope and the accompanying Thermo Scientific OMNICxi Raman imaging software. The obtained spectra are presented in Figure 9. The author concluded that Raman microscopy allows the analysis of particles below 1-micron size and the correct identification of plastic materials as well as inorganic materials such as titanium dioxide or other additives.

The Raman techniques have one major advantage over FTIR, which is its ability to identify particles up to $500 \mathrm{~nm}$ in size [80]. By comparison with reference spectra or standard library spectra (e.g from GRAMS software), specific plastic polymers can be identified within minutes. Accordingly, RMS allows broad range of detection and quantification of very small plastic particles of sizes $<1 \mu \mathrm{m}$ [7,35] and when combined with Raman spectral imaging, spatial chemical images can be produced based on the Raman spectra of a sample. This was recently demonstrated by researchers [81]. Cole et al [7] demonstrated that polymer particles within biological tissues with subcellular precision can be located with Raman technique when coupled with confocal laser-scanning microscopy. One limitation of this technique is drawn from its inability to measure laser excited fluorescent samples (e.g. residues of biological origin from samples) as they block the generation of interpretable Raman spectra [38].Generally, lower laser wave lengths

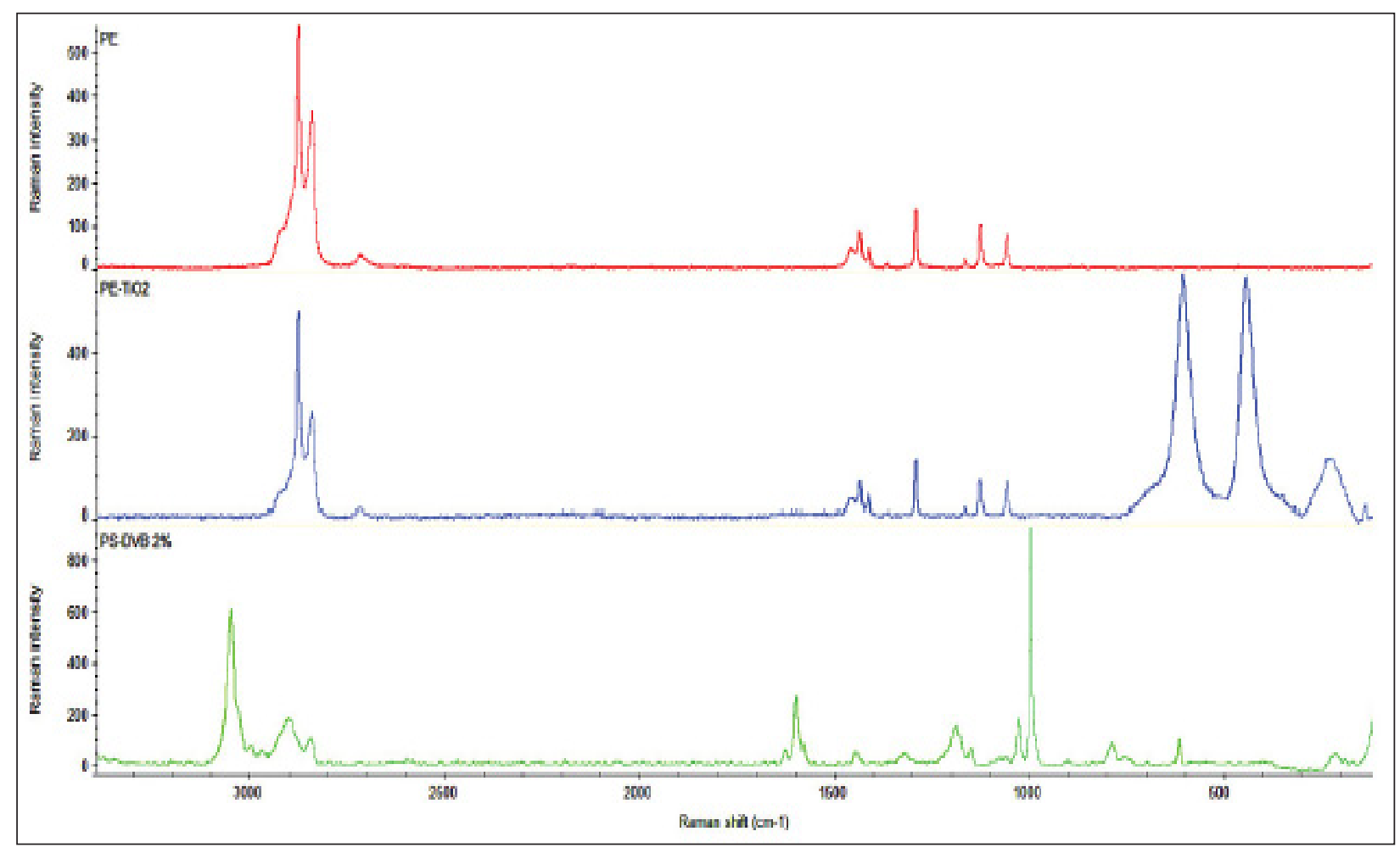

Fig. 9. Raman spectra of PE - polyethylene; PE-TiO2 polyethylene-titanium dioxide and PS-DVB - polystyrenedivinylbenzene microplastic standards [81]. 
transmit high energy result and signal intensity but also in a high fluorescence. Therefore, higher laser wavelengths greater than $1000 \mathrm{~nm}$ will minimize fluorescence but the lower energy of the laser results in a lower signal of the polymer sample. More study is required to find the optimum wave length of the laser light which will address this problem of fluorescence and low intensity for assessments of microplastics in environmental samples. In line, [38] recommended that fluorescence should be prevented through a sample pre-purification step prior to measurements for a clear identification of the polymer type of microplastic particles

Raman spectroscopy and FTIR are complementary techniques. Molecular vibrations, which are Raman inactive are IR active and vice versa and can thus provide complementary information on microplastic samples [38].

\subsection{Scanning electron microscopy with energy- dispersive $x$-ray spectroscopy (SEM/EDS)}

Scanning Electron Microscopy (SEM) magnifies a specific sample region using a high energy focused beam of electrons. The analyzed region evaluated with SEM can also be assayed for specific elements using Energy Dispersion Spectroscopy (EDS). SEM generates micrographs while EDS provides concentration of chemical composition of the sample. Thus the combined technique is referred to as SEM/EDS or SEM/EDX Analysis. The SEM/ EDS method enables the detection of microplastics and its degradation process in a sample due to its micro-scale and nano-scale features with magnification up to 500,000x $[15,36]$. The method determines particle sizes and elemental composition of microplastics in your test sample. It can only be performed only on solid samples [82].

A key factor in SEM is the interaction volume, which depends on the accelerating voltage of the electron beam and other factors including specimen nature, composition and sample preparation. The higher the accelerating voltage applied, the larger the interaction volume. This is turn determines the emission depth of the different signals used. The emission of secondary electrons (topography) and backscattered electrons (atomic number) are used to generate micrographs in SEM. Thereby providing information on topography, morphology, composition and crystallographic nature of microplastics in an environmental sample [83]. This method has been used to detect microplastics particles in sample [15,36]. Vianello [15] analysed sediments collected from Lagoon of Venice in Italy using SEM to characterize the surface morphology of the microplastic particles. Result showed irregular shapes and similar surface textures for several microplastics in contrast with comparable amorphous and regular surfaces of other plastic microfibers. Furthermore, the method revealed possible occurrence of degradation processes by showing images of weakened surfaces caused by adhering particles [15]. Imhof et al. [36] identified degraded microplastics in sediments of subalpine lake beach using SEM imaging. Many of the PP microplastics showed cracks, pits, grooves, disintegration, and adherent and attached diatoms. A typical SEM image of microplastic particles is presented in Figure 10.

Whilst SEM is effective for identification, EDS helps in quantification. In addition, SEM/ EDS analyses have been conducted on ocean trawl and fish gut for microplastics by [40] and [67]. Potential microplastics using particle morphology and elemental chemistry profiles have been tested by Wagner et al [40]. The analytical instrument used has been FEI XL30 Environmental SEM and a Thermo Fisher Scientific Noran System 7 EDS System. Moreover, samples has been imaged at 50x - 10,000x using an atomic number sensitive, backscattered electron (BSE) detector with a resolution of approximately $0.1 \mu \mathrm{m}$ [67] reported that SEM/EDS is effective in identifying chlorinated plastics such as polyvinyl chloride (PVC) due to their unique elemental signatures. Typical SEM-EDS results for microplastics in an environmental sample are shown in Figure 11.

The technique (SEM/EDS) has been used in identification of plastic additives of inorganic origin contained in microplastic particles, characterization and toxic chemicals extracted from microplastics 

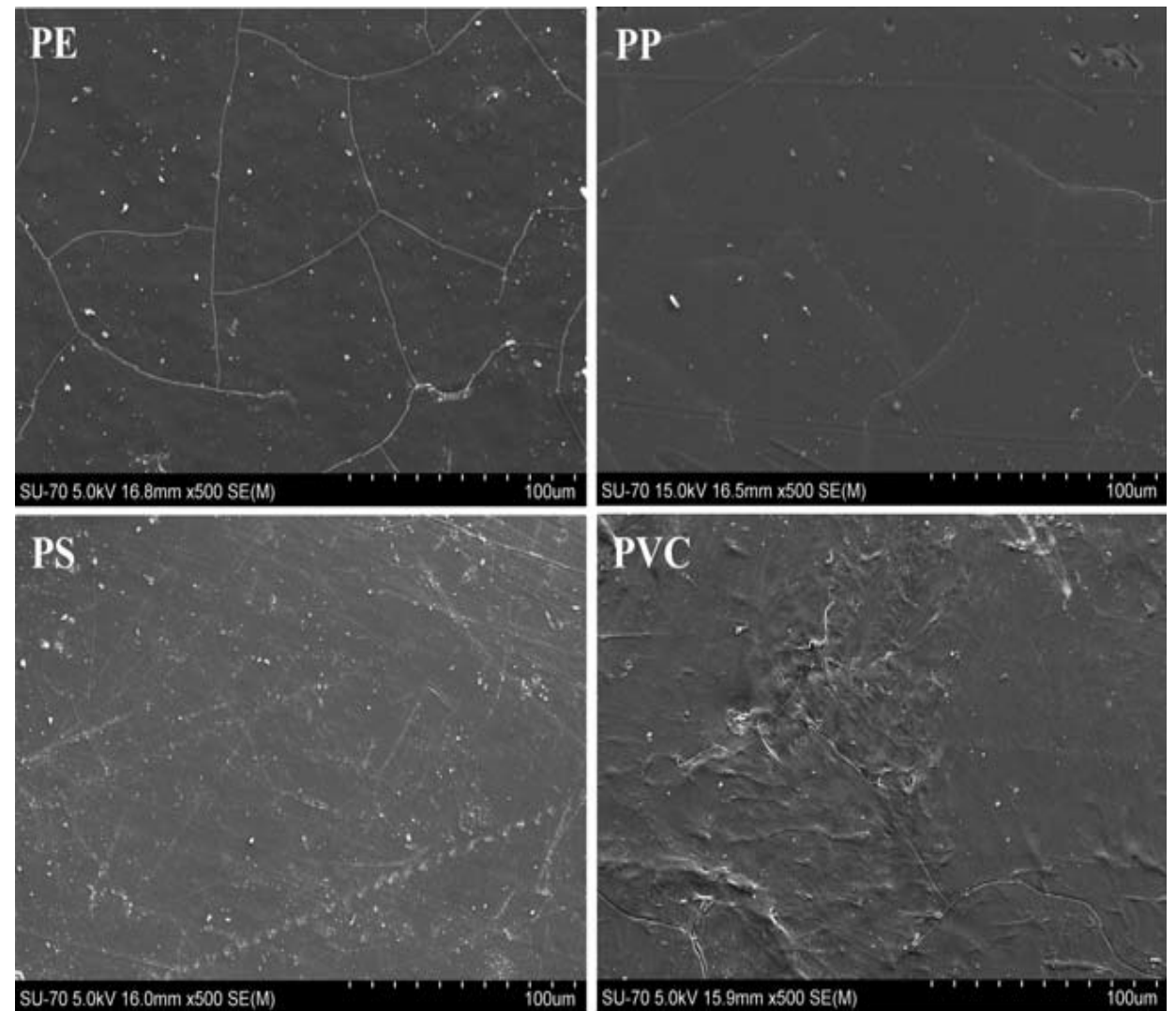

Fig. 10. Scanning electron microscopy images showing the surface of several thermoplastics: polyethylene (PE), polypropylene (PP), polystyrene (PS) and polyvinyl chloride (PVC) [83].

in samples from the North Pacific Gyre by Mendoza and Jones [84]. SEM-EDS have become an indispensable tool for analysis microplastic particles present in a sample. This method enables scientists to monitor how plastics degrade to form microplastic particles, emergent pollutants expressively threatening biota life $[61,83]$.

The limitation of quantitative SEM-EDS is that, this technique should only be carried out in flat polished samples or very thin films with irrelevant topography. Prior to spectra acquisition for quantification purpose, it is imperative that several well-assigned spectra with sufficient X-ray counts have been previously collected (serving as a reference). Then, the spectra need to be processed with matrix corrections with oxygen calculated by stoichiometry and the appropriate ZAF (the atomic number-Z, absorption-A and fluorescence-F correction) procedure. Again, EDS software applies the ZAF correction and carries out subsequent integration of the peaks to give the final semiquantification of the elements present in the specimen. Nevertheless, the user should be as critical as possible when accepting each step of the quantification process provided by the software [85].

\section{Conclusions}

This study reviewed spectroscopic techniques for quantifying and identification of microplastics in an environmental sample. Generally, for microplastics particles $<500 \mu \mathrm{m}$, spectroscopic techniques is important for their identification while the quality of result obtained strongly rely on good sampling and effective sample purification. During purification aggressive agents (e.g. strong acidic or alkaline solutions) should be avoided to conserve the whole plastic spectrum and because aggressive solutions negatively affect certain plastic polymer. Also, ordinary visual inspection of samples alone is insufficient but when in tandem with optical microscope it becomes effective, especially, in the case of particles $<500 \mu \mathrm{m}$. In 

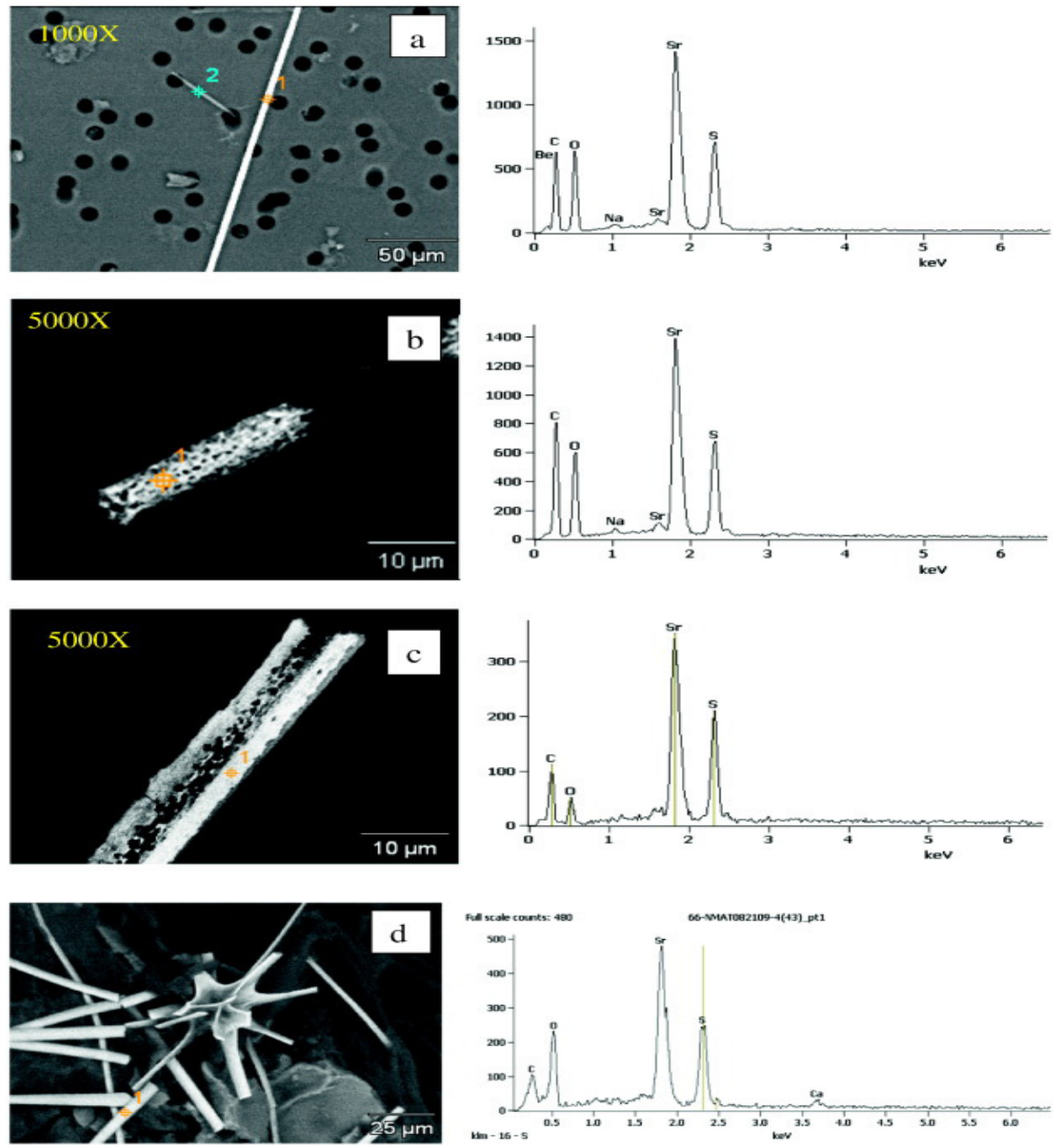

Fig. 11. Typical SEM-EDS results for microplastics in an environmental sample [67].

addition, CHN analyzer, pyrolysis-GC/MS and SEM-EDS have been used effectively for sample identification and quantification. The former which is based on combustion techniques works better for larger particle while SEM-EDS techniques is a better update to optical microscopy by providing information on the degradation process of plastic particles. A spectroscopic verification of microplastic particles by micro-FTIR or microRaman spectroscopy is essential and has also been used successfully for analyzing the particles of microplastics. Micro-Raman spectroscopy is very effective for microplastic particles of $<1$ $\mu \mathrm{m}$. Furthermore, spectroscopic techniques create an added value as they also provide information on the polymer composition. However, some of the discussed methods have its drawbacks in their use which include cost effectiveness, time consuming and difficulty to use (especially if you are inexperienced) like pyrolysis-GC/MS where samples have to be placed manually.

Finally, microplastics have been studied with non destructive methods often a combination of two methods: one separating and the other quantifying. It could be observed that since microplastics undergo very few reactions, their identification and quantification can be problematic more so in living tissue where there is no harm reported as at the time of this study. However, microplastics have become a cause for concern and advance studies are required to unravel the potential risk of their presence in our food and environment.

\section{Conflicts of interest}

The authors declare no conflicts of interest 


\section{Acknowledgement}

This research did not receive any specific funding

\section{Nomenclatures (Abbreviations)}

NOAA: National Oceanic and Atmospheric

Administration;

POPs: Persistent organic pollutants;

PAHs: Polyaromatic hydrocarbons;

OCPs: Organochlorine pesticides;

PCBs: polychlorinated biphenyls;

WHO: World Health Organization;

SOP: standard operation protocols;

FTIR: Fourier Transform infrared spectroscopy;

SEM-EDS: scanning electron microscopy energydispersive X-ray spectroscopy (SEM-EDS);

PyrGC/MS: pyrolysis- chromatography/mass

spectrometry;

TD-GC/MS: thermal desorption-gas

chromatography/mass spectrometry;

GC: gas chromatography;

MS: mass spectroscopy;

TCD: thermal conductivity detector;

OPAs: organic plastic additives;

HDPE, LDPE: high-density and low-density

polyethylene;

ATR: Attenuated Total Reflectance (ATR);

FPA: Focal Plane Array-Based Reflectance;

RMS: Raman micro-spectroscopy;

CCD: charge-coupled device;

PMT: photomultiplier tube;

UV: Ultraviolet;

PE: polyethylene;

$\mathrm{PE}-\mathrm{TiO}_{2}$ : polyethylen-titanium dioxide;

PS-DVB: polystyrene-divinylbenzene;

SEM: Scanning Electron Microscopy;

EDS: Energy Dispersion Spectroscopy;

PP: polypropylene;

PS: polystyrene;

PVC: polyvinyl chloride;

ZAF: atomic number-Z, absorption-A and fluorescence-F.

\section{References}

[1] R.U. Halden, Plastics and public health, Annu. Rev. Pub. Health, 31 (2010) 179-194.

[2] Statista, Production of plastics worldwide from 1950 to 2017 in million metric tons, 2018. https://www. statista.com/statistics/282732/global-productionof-plastics-since-1950/

[3] R.C. Thompson, Plastic debris in the marine environment:consequences and solution, marine nature conservation in Europe, federal agency for nature conservation, Stralsund, 2006.

[4] J.G. Derraik, The pollution of the marine environment by plastic debris: a review, Marter. Poll. Bull., 44 (2002) 842-852.

[5] C.J. Moore, G. L. Lattin, A.F. Zellers, Density of plastic particles found in zooplankton trawls from coastal waters of California to the north pacific central gyre, The plastic debris river to sea conference, Redondo Beach, California, 2005.

[6] D. Barnes, F. Galgani, R. Thompson, M. Barlaz, Accumulation and fragmentation of plastic debris in global environments. Philo. Trans. Royal Soc. B, 364 (2009) 985-998.

[7] M. Cole, P. Lindeque, C. Halsband, T. S. Galloway, Microplasticsas contaminants in the marine environment: a review. Mar. Poll. Bull, 62 (2011) 2588-2597.

[8] Greenfacts, Marine Litter: What are micro-plastics and how do they enter the marine environment? (2018). https://www.greenfacts.org/en/marinelitter/1-2/3-micro-plastics.htm [Accessed 09 May 2018].

[9] E.R. Graham, J.T. Thompson, Deposit- and suspension-feeding sea cucumbers (Echinodermata) ingest plastic fragments. J. Exp. Mar. Bio. Eco. 368 (2009) 22-29.

[10] K. Betts, Why small plastic particles may pose a big problem in the oceans, Env. Sci. Tech, 42(2008) 8995-8999.

[11] M.A. Browne, A. Dissanayake, T.S. Galloway, D.M. Lowe, R.C. Thompson, Ingested microscopic plastic translocates to the circulatory system of the mussel, Mytilus edulis (L), Env. Sci. Tech, 42 (2008) 5026-5031

[12] M.A. Browne, P. Crump, S.J. Niven, E. Teuten, A. Tonkin, T. Galloway, Accumulation of microplastic on shorelines worldwide: Sources and sinks, Env. Sci. Tech, 45 (2011) 9175-9179. 
[13] M. Claessens, S. De Meester, L. Van Landuyt, K. De Clerck, C. R. Janssen, Occurrence and distribution of microplastics in marine sediments along the Belgian coast. Mar. Poll. Bull, 62 (2011) 2199-2204.

[14] J. Hammer, M.H. Kraak, J.R. Parsons, Plastics in the marine environment: the dark side of a modern gift". Reviews of environmental contamination and toxicology, 220 (2012) 1-44.

[15] A. Vianell, A. Boldrin, P. Guerriero, V. Moschino, R. Rella, A. Sturaro, Microplastic particles in sediments of Lagoon of Venice, Italy: First observations on occurrence, spatial patterns and identification. Estuarine, Coastal and Shelf Sci, 130 (2013) 54-61.

[16] L. Van Cauwenberghe, A. Vanreusel, J. Mees, C.R. Janssen, Microplastic pollution in deep-sea sediments. Env. Poll, 182 (2013) 495-499.

[17] K.L. Ng, J.P. Obbard, Prevalence of microplastics in Singapore's coastal marineenvironment, Mar. Poll. Bull, 52 (2006) 761-767.

[18] T. Bowmer, P. Kershaw, Bioaccumulating and Toxic Substances in the Oceans, In: Proceedings of the GESAMP International Workshop on Microplastic Particles as a Vector in Transporting Persistent, (2010).

[19] S. Endo, R. Takizawa, K. Okuda, H. Takada, K. Chiba, H. Kanehiro, H. Ogi, R. Yamashita, T. Date, Concentration of polychlorinated biphenyls (PCBs) in beached resin pellets: variability among individual particles and regional differences, Mar. Poll. Bull., 50 (2005) 1103-1114.

[20] Y. Mato, T. Isobe, H. Takada, H. Kanehiro, C. Ohtake, T. Kaminuma Plastic resin pellets as a transport medium for toxic chemicals in the marine environment, Env. Sci. Tech., 35 (2001) 318-324.

[21] L. M. Rios, C. Moore, P.R. Jones, Persistent organic pollutants carried bysynthetic polymers in the ocean environment, Mar. Poll. Bull, 54 (2007) 1230-1237.

[22] A.A. Koelmans, E. Besseling, E.M. Foekema, Leaching of plastic additives tomarine organisms, Env. Poll, 187 (2014) 49-54.

[23] C. M. Rochman, E. Hoh, T. Kurobe, S.J. Teh, Ingested plastic transfers hazardouschemicals to fish and induces hepatic stress, Scientific Reports, 3 (2013) 3263.

[24] L.A. Holmes, A. Turner, R.C. Thompson,
Adsorption of trace metals to plastic resin pellets in the marine environment, Env. Poll., 160 (2012) 42-48.

[25] C.M. Rochman, B.T. Hentschel, S.J. Teh, Longterm sorption of metals is similar among plastic types: implications for plastic debris in aquatic environments, PLoS One, 9 (2014) 85433.

[26] K. Ashton, L. Holmes, A. Turner, Association of metals with plastic production pellets in the marine environment, Mar. Poll. Bull., 60 (2010) 20502055 .

[27] L.A. Holmes, A. Turner, R.C. Thompson, Interactions between trace metals and plastic production pellets under estuarine conditions, Marine Chemistry, 23 (2014) 1-8.

[28] F. Murray, P.R. Cowie, Plastic contamination in the decapod crustacean Nephrops norvegicus, Mar. Pollu. Bull, 62 (2011) 1207-1217.

[29] A. Ugolini, G. Ungherese, M. Ciofini, A. Lapucci, M. Camaiti, Microplastic debris in sandhoppers. Estuarine, Coastal and Shelf Sci., 129 (2013) 1922.

[30] E.M. Foekema, C. De Gruijter, M.T. Mergia, J.A. van Franeker, A.J. Murk, A.A. Koelmans, Plastic in North Sea fish, Env. Sci. Tech., 47 (2013) 88188824.

[31] S.L. Wright, R.C. Thompson, T.S. Galloway, The physical impacts of microplastics on marine organisms: A review, Env. Poll., 178 (2013) 483492.

[32] S.L. Wright, F.J. Kelly, H. Ren, Plastic and Human Health: A Micro Issue, Environ. Sci. Technol, 51(2017) 6634-6647.

[33] G. Readfearn, The Guardian WHO launches health review after micro-plastics found in $90 \%$ of bottled water, Water Res., 2 (2018) 1-47.

[34] V. Hidalgo-Ruz, L. Gutow, R.C. Thompson, M. Thiel, Micro-plastics in the marine environment: a review of the methods used for identification and quantification, Env. Sci. Tech., 46 (2012) 30603075 .

[35] M. Claessens, L. Van Cauwenberghe, M.B. Vandegehuchte, C.R. Janssen, New techniques for the detection of microplastics in sediments and field collected organisms, Mar. Poll. Bull., 70 (2013) 227-233.

[36] H.K. Imhof, J. Schmid, R. Niessner, N.P. Ivleva, C. Laforsch, A novel, highly efficient method for the 
separation and quantification of plastic particles in sediments of aquatic environments, Limnology and Oceanography: Meth., 10 (2012) 524-537.

[37] M.T. Nuelle, J. H. Dekiff, D. Remy, E. Fries, A new analytical approach for monitoring micro-plastics in marine sediments, Env. Poll., 184 (2014) 161169.

[38] G.J.L. Martin, G. Gunnar, Methodology Used for the Detection and Identification of Microplastics-A Critical Appraisal. M. Bergmann (eds.), Mar. Anthropo. Lit. Chap., 8 (2015) 201-227.

[39] M. Kedzierski, V. Le Tilly, P. Bourseau, H. Bellegou, G. César, O. Sire, Microplastics elutriation from sandy sediments: A granulometric approach, Mar. Poll. Bull., 107 (2016) 315-323.

[40] J. Wagner, Z. Wang, S. Ghosal, C. M. Rochman, M. Gassel and S. Wall, Novel Method for the Extraction and Identification of Microplastics in ocean trawl and fish gut matrices, Anal. Meth., 9 (2016) 1479-1490.

[41] S. Klein, I.K. Dimzon, T.P. Knepper, Analysis, Occurrence, and Degradation of Microplastics in the Aqueous Environment. M. Wagner, S. Lambert (eds.), Freshwater Microplastics, Hdb. Env. Chem., 58 (2018) 51-62.

[42] E. N. Verla, M.J. Horsfall, A.I. Spiff, Physico chemical Characterization of Playgrounds Soils of public Schools in Owerri Metropolis, Imo State, Nigeria. Int. J. Inn. App. Studies, 13 (2015) 472480.

[43] E.N. Verla, A.W. Verla, C.E. Enyoh, Pollution Assessment Models Of Soils In Portharcourt City, Rivers State, Nigeria. Wor N. Nat. Sci., 12 (2017) 1-23.

[44] C.E. Enyoh, E.A. Ihionu, A.W. Verla, P. N. Ebosie, Physicochemical Parameter Of Palm Oil And Soil From Ihube Community, Okigwe, Imo State Nigeria, Int. Letters Nat. Sci., 62 (2017) 35-43.

[45] C.E. Enyoh, A.W. Verla, N.J. Egejuru, pH variations and chemometric assessment of borehole water in Orji, Owerri Imo State, Nigeria. J. Env. Anal. Chem., 5 (2018) 1-9.

[46] A. W. Verla, E. N. Verla, C. E. Amaobi, C. E., Enyoh Water Pollution Scenario at River Uramurukwa Flowing Through Owerri Metropolis, Imo State, Nigeria. Int. J. App. Sci. Res., 3 (2018) 40-46.

[47] L. Jing, Risk Assessment of Heavy Metals in Surface Sediments from the Yanghe River, China.
Int. J. Environ. Res. Public Health, 11 (2014) 12441-12453.

[48] R.C. Thompson, Y. Olsen, R.P. Mitchell, A. Davis, S.J. Rowland, A.W. John, Lost at sea: where is all the plastic?, Sci., 304 (2004) 838-838.

[49] Y.K. Song, S.H. Hong, M. Jang, G.M. Han, M. Rani, J. Lee, A comparison of microscopic and spectroscopic identification methods for analysis of microplastics in environmental samples. Mar. Poll. Bull., 93 (2015) 202-209.

[50] J.P.W. Desforges, M. Galbraith, N. Dangerfield, P.S. Ross, Widespread distribution of microplastics in subsurface seawater in the NE Pacific Ocean, Mar. Poll. Bull., 79 (2013) 94-99.

[51] G. Erni-Cassola, M.I. Gibson, R.C. Thompson, J.A. Christie-Oleza, Lost, but Found with Nile Red: A Novel Method for Detecting and Quantifying Small Microplastics (1 mm to $20 \mu \mathrm{m}$ ) in Environmental Samples, Env. Sci. Tech., 5 (2017) 13641-13648.

[52] T. Maes, J. Rebecca, W. Nikolaus, H. Karsten, G.M. Andrew, A rapid-screening approach to detect and quantify microplastics based on fluorescent tagging with Nile Red. Scientific Reports, 7 (2017) 44501.

[53] S.M. Angel, T.J. Kulp, T.M. Vess, Remote-Raman Spectroscopy at Intermediate Ranges Using LowPower cw Lasers, Appl. Spectrosc., 46 (1992) 1085-1091.

[54] R. Goodacre, D.B. Kell, Pyrolysis mass spectrometry and its applications in biotechnology, Curr. Op. Biotech, 7 (1996) 20-28.

[55] G. Guido, Characterization of Polymers and Plastics Using an Elemental Analyzer, (2016).

[56] K. Liliana, G. Guido, Characterization of Polymers and Plastics (pellets, powders and films) by the Thermo Scientific FLASH 2000 Elemental Analyzer, Application note, 42230 (2016) 1-5.

[57] S. Morét-Ferguson, K.L. Law, G. Proskurowski, E.K. Murphy, E.E. Peacock, C.M. Reddy, The size, mass, and composition of plastic debris in the Western North Atlantic Ocean, Mar. Poll. Bull., 60 (2010) 1873-1878.

[58] P.M. Peacock, C.N. McEwen, Mass Spectrometry of Synthetic Polymers, Anal. Chem., 78 (2006) 3957-3964.

[59] R. K. Erwin, K. Mitsuhiro, G. Margit, J. Hans-Gerd, Hyphenation of aqueous liquid chromatography to pyrolysis-gas chromatography and mass spectrometry for the comprehensive 
characterization of water-soluble polymers, J. Chrom. A,1186 (2008) 222-227.

[60] P. Eckerle, M. Pursch, H.J. Cortes, K. Sun, B. Winniford, J. Luong, Determination of shortchain branching content in polyethylene by pyrolysis comprehensive multidimensional gas chromatography using low thermal mass column technology, J. Sep. Sci, 1 (2008) 3416-3422.

[61] E. Fries, J.H. Dekiff, J. Willmeyer, M.T. Nuelle, Ebert M., D. Remy, Identification of polymer types and additives in marine microplastic particles using pyrolysis-GC/MS and scanning electron microscopy, Environ. Sci. Process Impacts, 15 (2013) 1949-1956.

[62] P. Kusch, Pyrolysis-Gas Chromatography/Mass Spectrometry of Polymeric Materials. Advanced Gas Chromatography-Progress in Agricultural, Biomedical and Industrial Applications, Dr. Mustafa Ali Mohd (Ed.), In. Tech., 6 (2012) 21-24.

[63] A.J. Underwood, M.G. Chapman, M.A. Browne, Some problems and practicalities in design and interpretation of samples of microplastic waste, Anal. Methods, 9 (2017) 1332-1345.

[64] T. Matthias, H. Elena, K.F. Elke, Nile Red Staining as a Subsidiary Method for Microplastic Quantification: A Comparison of Three Solvents and Factors Influencing Application Reliability, DRP J. Earth Sci. Env. Studies, 2 (2017) 1-8.

[65] R, Geyer, J.R. Jambeck, K.L. Law, Production, use, and fate of all plastics ever made, Law Sci. Adv. 3 (2017).

[66] W. J. Shim, Y.K. Song, S.H. Hong, M. Jang, Identification and quantification of microplastics using Nile Red staining, Mar. Poll. Bull, 104 (2016) 109-117.

[67] Z.M. Wang, J. Wagner, S. Ghosal, G. Bedi, S. Wall, SEM/EDS and optical microscopy analyses of microplastics in ocean trawl and fish guts. Sci. Total. Environ, 603-604 (2017) 616-626.

[68] M. Eriksen, S. Mason, S. Wilson, C. Box, A. Zellers, W. Edwards, Microplastic pollution in the surface waters of the Laurentian Great Lakes, Mar. Poll. Bull. 77 (2013) 177-182.

[69] M. Kerstin, N. Fredrik Screening Of Microplastic Particles In And Down-Stream A Wastewater Treatment Plant. IVL Swedish Environmental Research Institute, Stockholm, (2014) 1-22.

[70] I. W. Levin, R. Bhargava Fourier transform infrared vibrational spectroscopicimaging: Integrating microscopy and molecular recognition, Annual Rev. Phys. Chem, 56 (2005) 429-474.

[71] J. P. Harrison, J.J. Ojeda, M.E. Romero-Gonzalez, The applicability of reflectance micro- Fouriertransform infrared spectroscopy for the detection of synthetic microplastics in marine sediments, Sci. Total. Environ, 416 (2012) 455-463.

[72] M. Bradley, S. Suja, L. Steven, W. Stephan, Tracking Microplastics in the Environment via FTIR Microscopy, Spectroscopy, 32 (2017) 17-23.

[73] S. Saarakkala, L. Rieppo, J. Rieppo, J. S. Jurvelin, Fourier Transform Infrared (FTIR) Microspectroscopy of Immature, Mature and Degenerated Articular Cartilage.Microscopy: Science, Technology, Applications and Education, A. Méndez-Vilas and J. Díaz (Eds.), Formatex (2010).

[74] S. T. Alexander, S. Melanie, P.H. Jesse, J.O. Jesús, Identification and quantification of microplastics in wastewater using focal plane array-based reflectance micro-FTIR imaging, Anal. Chem, 87 (2015) 6032-6040.

[75] M. M. Reddy, M. Deighton, R.K. Gupta, S.N. Bhattacharya, R. Parthasarathy, Biodegradation of oxo-biodegradable polyethylene. J Appl. Polym. Sci,. 111 (3) (2009) 1426-1432.

[76] S. Schlücker, Design and synthesis of Raman reporter molecules for tissue imaging by immunoSERS microscopy, J. Biophotonics, 4 (2011) 453463.

[77] D.N. Sathyanarayana, Vibrational spectroscopy: theory and applications, book, 2015.

[78] P.D. Taylor, O. Vinn, A. Kudryavtsev, J.W. Schopf, Raman spectroscopic study of the mineral composition of cirratulid tubes (Annelida, Polychaeta), J. Struc. Bio, 171 (2010) 402-405.

[79] G. Adrian, C.P. flavius, S. Virginie, S. Chris, N. Ioan,Applications of Raman micro-spectroscopy to stem cell technology: label-free molecular discrimination and monitoring cell differentiation, EPJ Tech. Instrument, 2 (2015) 6-9.

[80] A. Kappler, F. Windrich, M.G.J. Loder, M. Malanin, Identification of microplastics by FTIR and Raman microscopy: a novel silicon filter substrate opens the important spectral range below $1300 \mathrm{~cm}^{-1}$ for FTIR transmission measuremen, Anal. Bional. Chem., 407 (2015) 6791-6801. 
[81] M. Rocchia, I. Ruff, A. Vianello, Microplastic identification and characterization by Raman imaging spectroscopy, Thermo, Fisher Scientific Inc., 8 (2017) 1-5.

[82] M. Tirrel, Fundamentals of polymer solutions, Talor and francis, 2018.

[83] M. Scimeca, S. Bischetti, H. Kaur Lamsira, R. Bonfiglio, E. Bonanno, Energy dispersive X-ray (EDX) microanalysis: A powerful tool in biomedical research and diagnosis, Eur. J. Histochem. 62 (2018) 2841

[84] L.M.R. Mendoza, P.R. Jones, Characterisation of microplastics and toxic chemicals extracted from microplastic samples from the North Pacific Gyre, Env. Chem., 12 (2015) 611-617.

[85] A.J. Garratt-Reed, D.C. Bell, Energy Dispersive X-Ray Analysis in the Electron Microscope, BIOS Scientific Publishers Limited, Oxford, 2003. 